\title{
RAYMOND WILLIAMS NO ESPAÇO DAS PRODUÇÕES DISCENTES NO ESTADO DE SÃO PAULO: USP, UNESP E UNICAMP (2004-2020) ${ }^{1}$
}

\author{
RAYMOND WILLIAMS IN THE SPACE OF STUDENT PRODUCTIONS IN THE STATE \\ OF SÃO PAULO: USP, UNESP E UNICAMP (2004-2020)
}

\section{RAYMOND WILLIAMS EN EL ESPACIO DE PRODUCCIONES ESTUDANTILES EN EL ESTADO DE SÃO PAULO: USP, UNESP Y UNICAMP (2004-2020)}

Hiago Vaccaro Malandrin ${ }^{2}$

\begin{abstract}
Resumo: Apresentaremos como, entre 2004 e 2020, a obra de Raymond Williams (1921-1988) ganha espaço nas produções discentes na USP, Unesp e Unicamp. Partindo da história da leitura de Franco Moretti, observamos como o movimento editorial dos anos 1970 que se ocupou de traduzir Williams também o colocou como referência para a área de humanidades no espaço universitário. Palavras-chave: Raymond Williams; produção acadêmica; circulação de impressos.
\end{abstract}

\begin{abstract}
We will present how, between 2004 and 2020, the work of Raymond Williams (19211988) gains space in student productions at USP, Unesp and Unicamp. Based on Franco Moretti's reading history, we observe how the publishing movement of the 1970s that took care of translating Williams also placed him as a reference for the area of humanities in the university space.
\end{abstract}

Keywords: Raymond Williams; academic productions; book circulation.

Resumen: Presentaremos cómo, entre 2004 y 2020, la obra de Raymond Williams (1921-1988) gana espacio en las producciones estudiantiles de la USP, Unesp y Unicamp. A partir de la historia de lectura de Franco Moretti a la circulación de los grabados, observamos cómo el movimiento editorial de los años setenta que se encargó de traducir a Williams lo colocó también como referente del área de las humanidades en el espacio universitario.

Palabras clave: Raymond Williams; producción académica; circulación de libros.

\section{Introdução}

Sob uma perspectiva mais geral, costumamos ler a recepção de Raymond Williams (19211988) no Brasil associada à recepção dos estudos culturais, situando o autor enquanto nome significativo à crítica cultural ${ }^{3}$. Isto porque, como nos conta Maria Cevasco, "Quando feito à maneira de Williams, os estudos culturais configuram-se como mais do que mera anotação dos objetos dos estudos antes restritos à análise e à delimitação da grande arte", de modo que sua novidade está na “demonstração do potencial cognitivo da crítica cultural" (CEVASCO, 2007, p. 16).

Por outro lado, partindo de uma perspectiva da história cultural, temos um conjunto de estudos contemporâneos que evidenciam como o processo de recepção de Williams, na verdade, ocorre em um momento anterior a discussão referente à disciplina de estudos culturais, colocando as obras do autor como fundamentais para a inauguração e o estabelecimento de uma tradição

\footnotetext{
${ }^{1}$ Este artigo é decorrente do mestrado financiado pela FAPESP (n. 2019/00323-0) intitulado "Sobre Raymond Williams e a perspectiva de natureza: a circulação transatlântica de 'O Campo e a Cidade' no Brasil (1989-2019)”.

${ }^{2}$ Universidade Estadual de Campinas.

${ }^{3}$ Mais sobre essa discussão indicamos o livro Para ler Raymond Williams de Maria Elisa Cevasco, em especial o capítulo "Para ler Raymond Williams: uma apresentação" (CEVASCO, 2001, p. 15-42).
} 
intelectual preocupada em conciliar cultura, sociedade e educação (PAIXÃO, 2018, p. 07). Partindo dessa perspectiva, pretendemos discutir neste artigo como as obras do autor galês Raymond Williams ganham espaço nas produções discentes do Estado de São Paulo a partir de 2004, data da primeira produção mapeada, em função do movimento editorial que se ocupa em traduzi-lo desde os anos 1970, por um esforço conjunto entre Anísio Teixeira e a já encerrada Companhia Editora Nacional. Avaliaremos também como esse movimento tem impacto nos usos que a obra de Williams terá nas produções discentes da Universidade de São Paulo (USP), da Universidade Estadual Paulista (Unesp) e da Universidade Estadual de Campinas (Unicamp).

A escolha por instituições da região Sudeste, em especial de São Paulo, se dá em função de alguns fatores previamente mapeados e que serão discutidos nesse artigo: (a) as editoras que traduzem e publicam Williams no Brasil estão situadas neste estado; (b) os acervos de universidades públicas localizados na região sudeste, em especial aqueles da USP, Unesp e Unicamp, concentram o maior montante de exemplares do autor galês no cenário uni versitário brasileiro (MALANDRIN, 2021, p. 103).

É importante ressaltar, de partida, que não nos propormos a analisar como as ideias contidas em diferentes livros de Williams migram e são apropriadas no Brasil através de sua tradução, de modo que voltaremos nossa atenção a averiguar como, através de uma tradição editorial, Williams passa a aparecer nas páginas de certas produções acadêmicas a partir de 2004. Para isso, nos utilizaremos de dados numéricos presentes em pesquisas prévias sobre a presença do autor no cenário universitário brasileiro e iremos combiná-los aos dados inéditos da presença de obras do autor em produções acadêmicas nas universidades selecionadas. Referente as instituições escolhidas, nosso recorte temático não se deu de forma fortuita, uma vez que USP, Unesp e Unicamp são as universidades brasileiras que apresentam o maior contingente de obras de Williams em seus acervos, ultrapassando a marca de 100 exemplares entre as diferentes obras de Williams ${ }^{4}$ (MALANDRIN, 2021, p. 133-144).

Para reconstruir a presença de Williams em função de um movimento editorial e de sua presença em espaços universitários, partiremos da análise da geografia que envolve seus impressos, a fim de evidenciar o que há e o que não há referente a essas obras e seus usos um dado "espaço real", aqui entendido como os espaços universitários em que as produções discentes são associadas. Utilizaremos, nos termos de Franco Moretti (2003, p. 13), uma metodologia de pesquisa voltada, primeiro, à apresentação de elementos visuais, como figuras e tabelas para, em seguida, construirmos nossa análise. Nesse processo, os dados introduzidos de forma condensada e organizada, não acompanham o texto como ornamentos do discurso, "mas como ferramentas analíticas: que dissecam o texto de uma maneira incomum, trazendo à luz relações que de outro modo ficariam ocultas" (MORETTI, 2003, p. 13).

O corpo do texto aqui apresentado terá como início a breve introdução do processo de recepção das obras de Raymond Williams no espaço editorial brasileiro já mapeado por outros autores, com destaque para Alexandro Henrique Paixão (2018), que procura mapear esse processo desde a escolha de Cultura e Sociedade como a primeira obra de Williams a ser traduzida para o vernáculo, ainda em 1969, e avança introduzindo cada uma das obras traduzidas do autor galês. Construída a trajetória editorial de Williams por meio dos dados de tradução e editoração, comentaremos também nessa seção sobre os dados referentes a presença de obras de Raymond Williams em acervos universitários brasileiros e o destaque para aqueles

\footnotetext{
${ }^{4}$ Numericamente, a Universidade de São Paulo (USP) apresenta 167 exemplares; a Universidade Estadual de Campinas (Unicamp) apresenta 106 exemplares; a Universidade Estadual Paulista (Unesp) apresenta 148 exemplares. Destacamos aqui também a Universidade Federal de Minas Gerais (UFMG) com 89 exemplares e a Universidade Federal de Rio Grande do Norte (UFRN) com 96 exemplares (MALANDRIN, 2021, p. 133-144).
} 
ligados a USP, Unesp e Unicamp ${ }^{5}$. Encerraremos essa etapa de nosso texto discutindo os fatores que nos levam a indicar uma centralidade proposta em São Paulo e suas adjacências, a indicando segundo a localização das editoras que se encarregam de traduzir Williams para o vernáculo e os desdobramentos e implicações dessa localização.

Na segunda seção do artigo analisaremos os dados referentes às produções acadêmicas que apresentam nas referências bibliográficas livros de Williams no vernáculo, tendo como referência os sistemas de consulta das universidades presentes em nosso recorte. Procuraremos analisar a relação entre o montante de exemplares encontrados por acervo universitário e os usos mapeados desses exemplares em produções discentes. Por fim, identificaremos os livros de Williams que apresentam um maior uso em produções acadêmicas e analisaremos sua distribuição em relação às diferentes áreas do conhecimento na USP, Unesp e Unicamp.

\section{Uma revisão da recepção de Raymond Williams no mercado editorial brasileiro}

Na visão de Franco Moretti, "situar um fenômeno literário em seu espaço específico mapeá-lo - não é a conclusão do trabalho geográfico; é seu início" (MORETTI, 2003, p. 17). E assim terá início também nosso artigo: iremos primeiro mapear a recepção de Williams no Brasil e a circulação de seus impressos, para que possamos, através da apresentação de tabelas e figuras, atingir o ponto da discussão em que iremos expor a presença do autor galês nas produções discentes da USP, Unesp e Unicamp.

Uma vez que citamos o conceito de circulação de um impresso em dados espaços, é importante lembrar que, nos termos de Márcia Abreu e Jean-Yves Mollier (2016, p. 10), esse conceito "afeta diretamente a ideia de fechamento sobre um território", de modo que as fronteiras, sejam elas linguísticas - superadas pelos processos de tradução -, sejam elas geográficas - reduzidas pelo comércio e transporte de impressos -, não representam nos dias de hoje uma adversidade para o trânsito de livros por diferentes espaços nacionais. Por outro lado, mesmo que superadas as fronteiras que envolvem a exportação ou importação de dados impressos, ainda temos a circulação desses impressos relacionada a uma ideia de "fechamento sobre um território" (ABREU; MOLLIER, 2016, p. 10). Temos assim duas variáveis importantes para o problema que nos propomos a discutir aqui: a circulação dos livros de Williams e o "fechamento" sobre um determinado território ou espaço - não necessariamente um todo nacional, como viremos a apresentar. Será a partir dessa ponderação sobre a ideia da circulação de impressos que iremos inicialmente procurar revisitar como se dá o processo de recepção e editoração de Raymond Williams no Brasil, para posteriormente entendermos como ele adentra o espaço das produções discentes no Estado de São Paulo, em particular na USP, Unesp e Unicamp.

A trajetória de Williams no espaço editorial brasileiro, conforme comenta Alexandro Paixão (2018, p. 06), é inaugurada em fins da década de 1960, com a escolha de Anísio Teixeira em elaborar e inserir a tradução de Culture and Society: 1780-1950 (1958) como precursor da "Coleção: Cultura, Sociedade e Educação" (CCSE), em parceria com a Companhia Editora

\footnotetext{
${ }^{5}$ Serão utilizados nesse estudo os seguintes acervos: UNIVERSIDADE DE SÃO PAULO. Biblioteca digital de Teses e Dissertações da USP, c2021. Página inicial. Disponível em: https://teses.usp.br/. Acesso em: 27 set. 2021; UNIVERSIDADE DE SÃO PAULO. Biblioteca digital de Trabalhos de conclusão de curso da USP, c2021. Página inicial. Disponível em: http://www.tcc.sc.usp.br. Acesso em: 27 set. 2021; UNIVERSIDADE ESTADUAL DE CAMPINAS. Base Acervus - Sistema de bibliotecas da Unicamp, c2021. Disponível em: http://acervus.unicamp.br. Acesso em: 27 set. 2021; UNIVERSIDADE ESTADUAL DE CAMPINAS. Sistema de bibliotecas da Unicamp, c2021. Disponível em: http://www.sbu.unicamp.br/sbu/. Acesso em: 27 set. 2021; UNIVERSIDADE ESTADUAL PAULISTA. Repositório Institucional UNESP, c2021. Página inicial. Disponível: em: https://repositorio.unesp.br. Acesso em: 27 set. 2021.
} 
Nacional. Mais do que simplesmente traduzir a obra de Williams com maior visibilidade no cenário britânico, a proposta contida dentro do programa da CCSE era aquilatar o repertório da área de humanidades, tendo o autor galês como uma das principais referências para o estudo das relações estabelecidas entre cultura, história e sociedade nos espaços brasileiros (PAIXÃO, 2018, p. 06). Nesse contexto, o nome de Williams, agora associado no Brasil a tradução elaborada por Anísio Teixeira - junto a Leônidas Hegenberg e Octanny Silveira da Mota - e a editoração da Nacional, veio a ocupar um papel inaugural dentro da tentativa de ampliar o comércio de livros com enfoque no público universitário no país (PAIXÃO, 2018, p. 06).

A partir da ação da Editora Nacional e a publicação da primeira tradução de Williams no vernáculo, encontramos em 1979 - dez anos após a tradução de Cultura e Sociedade -, os primeiros passos de uma tradição editorial preocupada em editorar e publicar grande parte da produção intelectual de Williams no Brasil. Este movimento encontra-se na Tabela 01 a seguir, que compila em ordem cronológica todas as traduções do autor para a língua portuguesa em um arco que compreende desde 1969 até a publicação de Televisão em 2016.

\begin{tabular}{|c|c|c|c|}
\hline Livro & Editora & $1^{\mathrm{a}} \mathrm{ed}$. & Tradutor \\
\hline $\begin{array}{c}\text { Cultura e sociedade: } \\
\quad 1780-1950\end{array}$ & $\begin{array}{c}\text { Companhia Editora } \\
\text { Nacional }\end{array}$ & 1969 & $\begin{array}{l}\text { Anísio Spínola Teixeira } \\
\text { Leônidas H. B. Hegenberg } \\
\text { Octanny Silveira da Mota }\end{array}$ \\
\hline Marxismo e literatura & Zahar & 1979 & Waltensir Dutra \\
\hline O campo e a cidade & Companhia das Letras & 1989 & Paulo Henriques Britto \\
\hline O povo das montanhas negras & Companhia das Letras & 1991 & Sergio Flaksman \\
\hline Cultura & Paz e Terra & 1992 & Lolio Lourenço de Oliveira \\
\hline Tragédia moderna & Cosac Naify & 2002 & Betina Bischof \\
\hline Palavras-chave & Boitempo & 2007 & Sergio Flaksman \\
\hline Drama em cena & Cosac Naify & 2010 & Rogerio Bettoni \\
\hline $\begin{array}{l}\text { O campo e a cidade } \\
\text { (edição de bolso) }\end{array}$ & Companhia das Letras & 2011 & Paulo Henriques Britto \\
\hline Cultura e materialismo & Editora Unesp & 2011 & André Glaser \\
\hline Política do modernismo & Editora Unesp & 2011 & André Glaser \\
\hline $\begin{array}{l}\text { Cultura e sociedade: } \\
\text { de Coleridge a Orwell }\end{array}$ & Vozes & 2011 & Vera Joscelyne \\
\hline A política e as letras & Editora Unesp & 2013 & André Glaser \\
\hline A produção social da escrita & Editora Unesp & 2014 & André Glaser \\
\hline Recursos da esperança & Editora Unesp & 2015 & $\begin{array}{c}\text { Nair Fonseca } \\
\text { João Alexandre Peschanski }\end{array}$ \\
\hline Televisão & PUC-Minas / Boitempo & 2016 & $\begin{array}{c}\text { Márcio Serelle } \\
\text { Mário F. I. Viggiano }\end{array}$ \\
\hline
\end{tabular}

Tabela 01 - Primeiras edições dos livros de Raymond Williams traduzidos para o vernáculo (1969-2016)

Fonte: Elaboração própria 
A tabela apresentada nos auxilia a compreender o processo de assimilação de Williams por parte das editoras nacionais a partir da tradição estreada em 1969, com destaque para as publicações que sucedem os anos 2000, marcadas por um novo impulso em traduzir o autor galês "por parte de editoras focadas no público universitário" (PAIXÃO, 2018, p. 09-10). O movimento editorial observado pode e então ser indicado como diretamente derivado do primeiro esforço de Anísio Teixeira em prover novas referências para os estudos brasileiros, em especial para a construção de um saber para "as humanidades no país", além de, em parceria com a Editora Nacional, "expandir o comércio de impressos com o enfoque no público universitário" (PAIXÃO, 2018, p. 09). Tal asserção torna-se mais evidente quando ponderamos sobre as editoras introduzidas na Tabela 01, de modo que a maior parte ou está localizada na cidade de São Paulo ou possui sua sede nessa cidade, com exceção da editora Zahar (sediada no Rio de Janeiro até sua compra, em 2019, pelo grupo Companhia das Letras) e da parceria com a PUC-Minas.

Para além das implicações comerciais, a expansão do mercado editorial direcionado a um público universitário também parece influenciar o espaço acadêmicos nacional, como observamos na Tabela 02 a seguir que nos dá os primeiros contornos de parte da "história da leitura, como chamamos hoje" (MORETTI, 2003, p. 153) que estamos analisando.

\begin{tabular}{c|c|c|c|c|c|c}
\hline Região & Sudeste & Sul & Centro-Oeste & Norte & Nordeste & Total \\
\hline $\mathrm{N}^{\mathrm{o}}$ de Exemplares & 1372 & 515 & 213 & 177 & 559 & 2836 \\
\hline
\end{tabular}

Tabela 02 - Primeiras edições dos livros de Raymond Williams traduzidos para o vernáculo (1969-2016) Fonte: adaptado de MALANDRIN, 2021, p. 133-144.

Os dados apresentados nos levam a observar o destaque numérico na região sudeste do país, que detém $48,3 \%$ do volume total de exemplares originais ou traduzidos de Williams que circulam em acervos universitários. Entretanto, a região Sudeste como um todo ainda é abrangente demais para nosso artigo, de modo que, para que possamos atingir a discussão referente a como a obra traduzida de Williams aparece nas produções discentes no Brasil, precisamos selecionar um recorte observável. Deste modo, para medirmos a variação interna de um sistema, como nos indica Moretti, é necessária "a seleção de uma amostra" (MORETTI, 2003, p. 186). Em outras palavras, para medirmos como a obra de Williams passa a ser referenciada em produções discentes, precisamos selecionar uma amostra que nos permita isolar nossa variável - as produções acadêmicas - dentro de uma amostra cabível, que neste caso será as universidades públicas do Sudeste com a maior concentração de exemplares de Williams no cenário brasileiro. Segundo estudos prévios, é conhecido que USP, Unesp e Unicamp detêm 421 dos 2836 exemplares de Williams que circulam nacionalmente em espaços universitários, o que corresponde a aproximadamente $20 \%$ dos exemplares espalhados pelo Brasil (MALANDRIN, 2021).

Deste modo, para a discussão que se segue neste artigo, iremos operar com acervos da USP, Unesp e Unicamp para observar como a obra de Raymond Williams passa a fazer parte das produções discentes dessas universidades

\section{A presença de Raymond Williams na produção discente paulista}

Como procuramos evidenciar brevemente, a tradição iniciada em meados de 1970 pela parceria entre Anísio Teixeira e a Companhia Editora Nacional coloca o nome de Raymond Williams dentro um movimento editorial que gradativamente passa a se destacar no Estado de São Paulo. Esse movimento, como iremos discutir agora, também traz implicações para o meio universitário, em 
especial nos espaços da USP, Unesp e Unicamp. Para averiguarmos essa assertiva, precisamos observar a geografia literária dos livros de Williams que circulam nas referidas universidades.

O termo "geografia literária" (MORETTI, 2003, p. 154) que empregamos aqui é o mesmo utilizado por Franco Moretti, o qual é construído por meio de uma história seriada. Ao selecionarmos parte da história da presença dos livros de Williams no país, estamos lidando com uma história seriada "artificial", isto porque "uma série nunca é 'encontrada', mas sempre construída” (MORETTI, 2003, p. 154).

\begin{tabular}{c|c|c|c|c}
\hline Livro & USP & UNICAMP & UNESP & Total \\
\hline O campo e a cidade & 27 & 20 & 25 & 72 \\
Cultura & 19 & 08 & 11 & 38 \\
\hline Cultura e sociedade & 18 & 07 & 10 & 35 \\
Palavras-chave & 14 & 10 & 11 & 35 \\
\hline Drama em cena & 11 & 05 & 10 & 26 \\
Recursos da esperança & 01 & 03 & 22 & 26 \\
\hline Cultura e materialismo & 03 & 04 & 11 & 18 \\
\hline Política do modernismo & 03 & 03 & 09 & 15 \\
\hline Tragédia moderna & 06 & - & 05 & 11 \\
\hline Marxismo e literatura & 01 & 01 & 04 & 06 \\
\hline O povo das montanhas negras & - & 03 & 03 & 06 \\
\hline A política e as letras & 02 & - & 02 & 04 \\
\hline A produção social da escrita & - & 01 & 02 & 03 \\
\hline Televisão & - & - & 02 & 02 \\
\hline
\end{tabular}

Tabela 03 - Distribuição das traduções de Raymond Williams na USP, Unesp e Unicamp (2020) ${ }^{6}$

Fonte: adaptado de MALANDRIN, 2021. p. 133-144

Desse mapeamento mais geral, como comentamos anteriormente, essas três universidades apresentam 419 exemplares de Williams, dos quais 291 compõe o conjunto de títulos em português apresentado na Tabela 03, ordenados pela quantidade de exemplares, ainda sem a discriminação entre diferentes edições.

De posse dos dados da presença de Williams nos acervos consultados, nos resta expor as produções discentes da USP, Unicamp e Unesp que apresentam livros de Raymond Williams nas referências bibliográficas, para que possamos, assim, operar com ambas variáveis.

\footnotetext{
${ }^{6}$ Para os dados apresentados foram averiguadas as produções acadêmicas disponibilizas nos seguintes bancos de dados: 1) USP: https://teses.usp.br/ e http://www.tcc.sc.usp.br; 2) Unesp: https://repositorio.unesp.br; 3) Unicamp: http://acervus.unicamp.br e http://www.sbu.unicamp.br/sbu/.
} 


\begin{tabular}{c|c}
\hline Produção Acadêmica & $\mathbf{N}^{\mathbf{0}}$ de produções \\
\hline Trabalho de conclusão de curso & 07 \\
Dissertação & 75 \\
Tese & 45 \\
\hline
\end{tabular}

Tabela 04 - Produções discentes da USP, Unicamp e Unesp que apresentam livros de Raymond Williams nas referências bibliográficas (2020) - Fonte: Elaboração própria

Os primeiros dados nos levam a ver como, entre as produções mapeadas, Williams ganha espaço na pós-graduação, em especial dentro de dissertações. Referente a isso, elaboramos algumas suposições, sendo a principal delas que esse destaque se dá em função dos nomes que orientam esses trabalhos. Partindo da hipótese de Paixão de que, como desdobramento subsequente do movimento editorial iniciado com Anísio Teixeira e a Companhia Editora Nacional, uma tradição universitária se instaura a partir da publicação do livro Para ler Raymond Williams (2001), da pesquisadora Maria Elisa Cevasco. Aqui, Williams é situado como um "dos principais críticos da cultura dentro de uma perspectiva materialista" (PAIXÃO, 2018, p. 15) em diálogo com intérpretes da cultura brasileira. A partir dessa tração universitária, imaginamos que a concentração de produções ligadas a pós-graduação se dê em função dessas mesmas produções serem orientadas por pesquisadores que, assim como Cevasco, acabam por inserir a obra de Williams no cenário universitário como um referencial teórico para diferentes pesquisas.

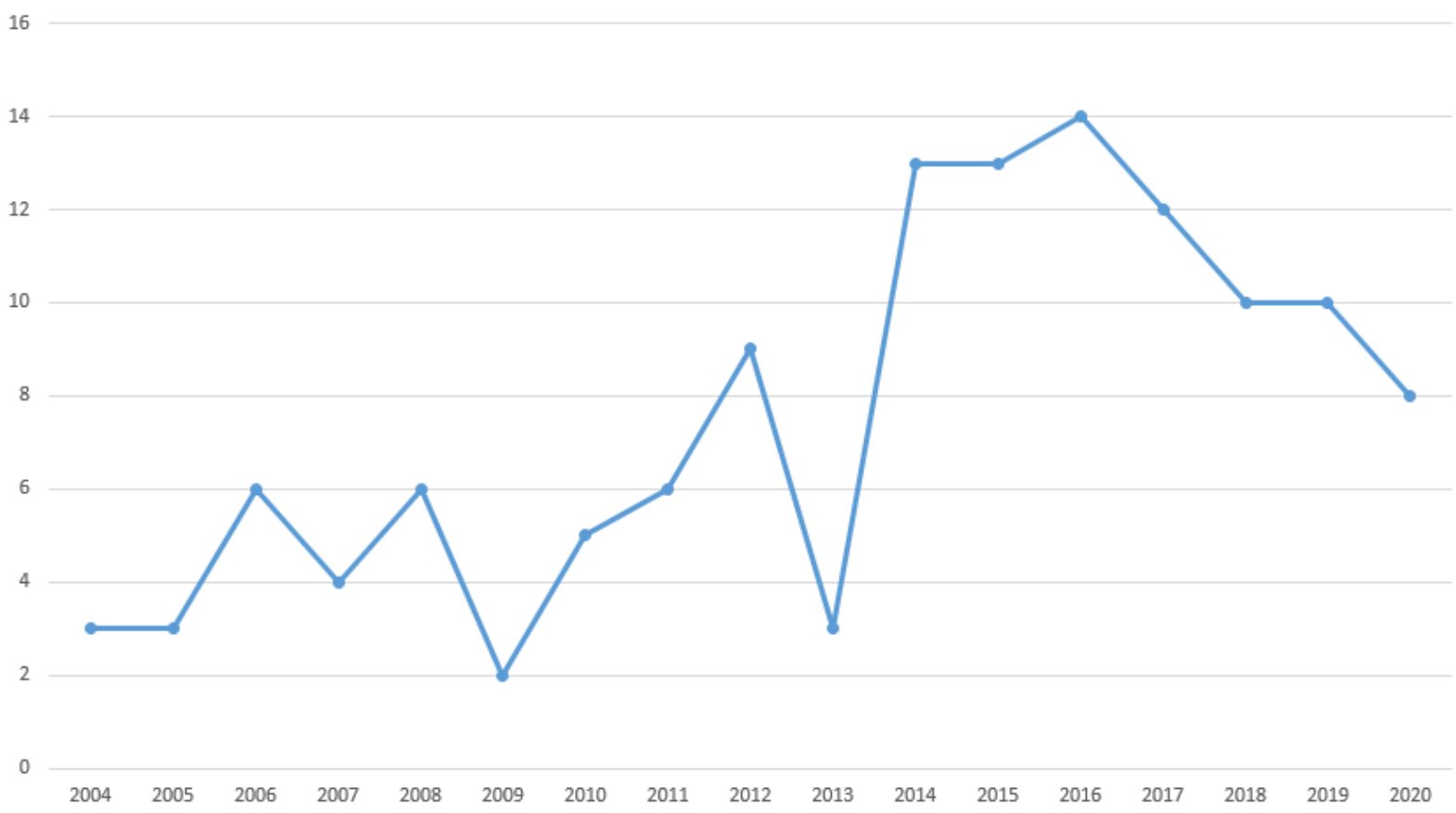

Figura 01 - Distribuição temporal das produções discentes que apresentam livros de Raymond Williams nas referências bibliográficas na USP, Unesp e Unicamp (2004-2020) - Fonte: Elaboração própria

De acordo com a Figura 01 temos notícia das primeiras produções discentes que apresentam Williams nas referências bibliográficas aparecendo após os anos 2000. Começando em 2004, observarmos uma gradativa progressão até o ano de 2016, quando atingimos o ponto mais alto de nosso gráfico. $\mathrm{O}$ ano de 2016, além do marco como ano em que mais são referenciadas obras de Williams, também conta com um outro ponto importante: é o ano da 
última publicação da tradução - até a escrita desse artigo - de um livro de Williams para o vernáculo. Esse destaque a partir do momento em que o maior conjunto de obras de Williams encontra-se traduzido no Brasil também nos revela que a tradição editorial iniciada em 1969 e que ainda vigora, uma vez que temos livros do autor não traduzidos - atingiu seu primeiro objetivo, colocando Williams e a temática geral de "cultura, sociedade e educação" em contato com os espaços universitários do país (PAIXÃO, 2018, p. 09).

Nesse contexto, Franco Moretti nos perguntaria: o que os dados apresentados nesses dois conjuntos nos mostram? E a resposta, partindo do exposto na Tabela 02 até os últimos dados apresentados, seria de que duas coisas muito diferentes se evidenciam: "o todo é bem ordenado - mas suas partes individuais são, ao contrário, bastante aleatórias" (MORETTI, 2003, p. 88). Nosso todo, entendido aqui como a região Sudeste, apresenta a maior parcela de exemplares de Williams que circulam em espaços acadêmicos brasileiros, do mesmo modo que dentro de nosso recorte local, entre USP, Unicamp e Unesp, os livros de Williams que se destacam são semelhantes nos três acervos. Por outo lado, quando voltamos nossa atenção a nossos indicadores individuais, ou seja, às produções discentes dessas três instituições, começamos a encontrar os chamados "dados dispersos".

Os dados apresentados na Tabela 04 e na Figura 01 deste modo direcionaram nossa pesquisa para a necessidade de uma análise minuciosa, a fim de localizar os títulos e volumes de livros de Williams referenciados no interior das produções discentes mapeadas, dados esses apresentados na Tabela 05.

\begin{tabular}{c|c}
\hline Título referenciado & $\mathbf{N}^{\mathbf{0}}$ de referências \\
\hline Cultura & 29 \\
\hline O campo e a cidade & 29 \\
\hline Cultura e sociedade & 22 \\
\hline Marxismo e literatura & 22 \\
\hline Cultura e materialismo & 21 \\
\hline Palavras-chave & 15 \\
\hline Tragédia moderna & 11 \\
\hline A política do modernismo & 04 \\
\hline Recursos da esperança & 04 \\
\hline A política e as letras & 04 \\
\hline Drama em cena & 04 \\
\hline
\end{tabular}

Tabela 05 - Títulos e quantidade de referências bibliográficas a livros de Raymond Williams nos acervos da USP, Unesp e Unicamp (2004-2020) - Fonte: Elaboração própria

Quando voltamos nossa atenção aos últimos dados apresentados, alguns títulos se evidenciam em questão da forte presença. Recuperaremos assim sete títulos dentre os onze apresentados na Tabela 05: Cultura; O Campo e a Cidade; Cultura e Sociedade; Marxismo e Literatura; Cultura e materialismo; Palavras-chave; Tragédia Moderna. Entretanto, antes de prosseguirmos com nossa exposição, precisamos contextualizar esses livros dentro de seus espaços específicos de utilização. Para isso, analisaremos as áreas do conhecimento as quais os trabalhos discentes que os mobilizam estão associados. 
Durante as pesquisas para a confecção das tabelas apresentadas neste artigo, tornou-se visível que dentre as três áreas mais gerais do conhecimento (humanas, exatas e biológicas) a produção discente que assimila Williams está localizada na área de humanas, em sua maioria dentro dos cursos de pós-graduação em história, letras e ciências sociais. Partindo do fato de que a produção de Williams circula sumariamente entre as humanidades, precisamos abarcar mais. Para isso, iremos avaliar como os livros de Williams que possuem mais de dez referências estão dispostos em diferentes cursos dentro das oito atuais áreas do conhecimento (ciências exatas e da terra; ciências biológicas; engenharias; ciências da saúde; ciências agrárias; linguística, letras e artes; ciências sociais aplicadas; ciências humanas).

\begin{tabular}{c|c|c|c|c}
\hline Título & Edição & $\begin{array}{c}\text { Ciências } \\
\text { Humanas }\end{array}$ & $\begin{array}{c}\text { Ciências Sociais } \\
\text { Aplicadas }\end{array}$ & $\begin{array}{c}\text { Linguística, } \\
\text { Letras e Artes }\end{array}$ \\
\hline Cultura e Sociedade & 1969 & 06 & 05 & 02 \\
Marxismo e literatura & 2011 & 05 & 04 & - \\
& 1979 & 11 & 06 & 05 \\
O campo e a cidade & 1989 & 15 & 01 & 03 \\
& 1990 & 02 & - & - \\
& 2000 & 01 & - & 04 \\
Cultura & 2011 & 06 & - & - \\
& 1992 & 09 & 09 & - \\
Tragédia moderna & 2000 & 05 & 01 & 05 \\
\hline Palavras-chave & 2002 & 06 & 01 & 04 \\
\hline Cultura e materialismo & 2011 & 12 & - & 02 \\
\hline
\end{tabular}

Tabela 06 - Distribuição das principais obras traduzidas de Raymond Williams em produções acadêmicas na USP, Unicamp e Unesp por área do conhecimento (2020) - Fonte: Elaboração própria

Os dados contidos na Tabela 06 caminham para lugares bastante específicos, de modo que isso nos auxilia a "estabelecer uma unidade" entre os diferentes títulos e edições encontrados (MORETTI, 2003, p. 140). Como dito, sete livros se destacam: Cultura; O Campo e a Cidade; Cultura e Sociedade; Marxismo e Literatura; Cultura e materialismo; Palavraschave; Tragédia Moderna; e observando-os, possuímos três conjuntos para esses livros, os quais, para que possamos caminhar para o final da discussão de nosso artigo, teremos quatro agrupamentos “e, naturalmente, a exceção" (MORETTI, 2003, p. 140).

Referente aos sete títulos apresentados e suas diferentes edições, temos exemplares de 1969 sendo referenciados, assim como também encontramos produções que referenciam traduções de 2011, o que nos confere um arco temporal de pouco mais de quarenta anos. Para além disso, recuperamos aqui também a descoberta da Figura 01 de que o pico de produções que carregam o nome de Williams é atingido em 2016, posteriormente a tiragem de todas as edições apresentadas na Tabela 06. O que tentaremos inferir, por fim, é como esses livros que 
se fazem mais presentes são, na verdade, uma consequência direta da tradição editorial iniciada em 1969 pela parceria entre Anísio Teixeira e a Companhia Editora Nacional.

Dos três conjuntos de livros que comentamos, podemos citar que o grupo A é composto, para além de Cultura e Sociedade, pelos títulos de Marxismo e Literatura e Cultura. Esses três livros estão diretamente atados a proposta intelectual de Anísio Teixeira e ao projeto contido na Coleção Cultura, Sociedade e Educação (CCSE), que tinham como objetivo ampliar a coleção de autores circulantes no meio universitário, situando Williams como fundamental para os temas que dão nome a Coleção. Essa apropriação gradativa do autor galês em função de seu debate referente a cultura e sociedade "se dá em virtude dos estudos do autor em como as formações sociais e culturais são interconstitutivas, são expressões diferentes da mesma maneira historicamente específica de fazer sentido da experiência do vivido", praticando a análise dessas formações como "um instrumento de descrição e de interpretação da sociedade que as molda" (CEVASCO, 2007, p. 16).

Nosso segundo conjunto é composto pelas diferentes edições de $O$ Campo e a Cidade: na história e na literatura. Embora o livro apresente pontos de contato com as demais produções de Williams, a presença desse livro em diferentes produções discentes nos revela um caminho diferente daquele apresentado no conjunto anterior. Enquanto Williams discute nas páginas de seu livro "representações dos diferentes papéis de campo e de cidade" no tecido literário e discurso histórico ingleses (WILLIAMS, 2000, p. 11) nos espaços universitários brasileiros o livro parece ganhar espaço em função da existência de um campo pré-formado de pensamento já consolidada no país que problematiza nos estudos brasileiros a relação entre os cenários rurais e urbanos e que possui uma geografia própria, "colocando o livro dentro dessa linha de pensamento" em particular (MALANDRIN, 2021, p. 89).

Tragédia Moderna é o título que completa nosso terceiro conjunto dentre as traduções mais presentes nas produções mapeadas. Nos termos de Williams, este livro contém uma intenção de escrita próxima a de Cultura e sociedade e The long revolution, diferenciando em temática dos outros livros do autor contidos na Tabela 06 ao apresentar "um apanhado histórico e crítico das ideias" de tragédia (WILLIAMS, 2002, p. 25), o que nos levou a colocá-lo em separado dos conjuntos anteriores. Embora não exista indicação prévia de uma tradição que se aproprie desse livro de Williams, indicamos aqui, tendo em vista tanto o volume de exemplares em acervos universitários nacionais quanto sua presença nas produções discentes observadas, que essa é uma hipótese para justificar os dados numéricos encontrados.

É importante mencionar que os títulos Cultura e Materialismo e Palavras-chave foram tratados como a chamada "exceção" na visão de Moretti. O primeiro é reunião de ensaios escritos por Williams em diferentes momentos da carreira e organizados sob a forma de um livro posteriormente, mas sem uma linearidade ao longo do impresso; e o segundo foi originalmente planejado como apêndice do livro Cultura e Sociedade, se tornando um livro independente em função de seu volume de informação. Indicamos esses títulos como exceção porque, apesar da forte presença desses títulos nos trabalhos mapeados, notamos que Cultura e Materialismo ocupa um papel bastante abrangente dentro dos trabalhos mapeados, não permitindo inferir uma uniformidade em sua presença, possivelmente em virtude das diferentes temáticas presentes no livro - ainda que exista uma centralidade na intenção proposta em seu interior -; por outro lado, com Palavras-chave observamos um uso comum dentro de nosso recorte, entretanto, esse uso tende a dar ao livro uma característica de apoio metodológico às pesquisas mapeadas, fazendo com sua presença se diferencie do grupo mais geral da temática de cultura. 


\section{Encaminhamentos finais}

A construção de nossa história seriada da presença de Williams em produções discentes, exposta ao longo das tabelas e figuras apresentadas, se deu até aqui em torno de tudo aquilo que se mostrou "repetível", permitindo, dessa maneira, que pudéssemos "transformar objetos distintos em uma série" (MORETTI, 2003, p. 154). Ou seja, operamos inicialmente com diferentes livros de Williams - nossos objetos distintos - para observarmos aquilo que era "repetível" entre os livros mais presentes nos acervos, do mesmo modo que procuramos novamente isolar o elemento que se repetia entre as referências a Williams ao selecionar os livros com maior número de citações para uma análise das edições mais presentes.

Todo trabalho construído foi metodologicamente construído em torno daquilo que se destaca ao observarmos a geografia de um impresso. A geografia, enquanto nosso entendimento mais básico, viceja na desigualdade entre seus elementos: "se rios, montanhas, cidades fossem distribuídos de modo igual em todos os lugares, [...] a geografia não existiria" (MORETTI, 2003, p. 154). E o mesmo vale para nós: se possuíssemos uma distribuição uniforme das obras de Williams no país não estaríamos produzindo uma geografia específica desse autor e do processo de apropriação do autor em determinados espaços acadêmicos. Para além disso, sabendo que "o pensamento de Williams impulsionou fortemente os estudos culturais que, a partir de suas obras fundamentais, espalhou-se para muitos outros lugares do mundo" (CEVASCO, 2007, p. 17), gostaríamos de recuperar também as palavras de Márcia Abreu e Jean-Yves Mollier para finalizar nosso texto, de modo que

Evitando tanto o eurocentrismo quanto o exotismo, enfatiza-se a ideia de circulação, pois o que interessa é observar o movimento entre Europa e Brasil e não o fluxo de ideia e mercadorias $d a$ Europa para o Brasil. Ou seja, interessa pensar mais em termos de conexão do que de dependência cultural, mais em termos de apropriação do que de influência. (ABREU; MOLLIER, 2016, p. 13).

Ainda que fale da cultura oitocentista, a citação revela o cerne do debate que aqui procuramos estruturar, enfatizando que sempre é válido revisitar as diversas e complexas relações transacionais - tanto antigas quanto contemporâneas -, procurando observar como diferentes produções d'além mar ganham espaço - e continuam ganhando - no cenário universitário nacional através de diferentes tradições editoriais. Temos assim que, mais do que um desdobramento do movimento editorial iniciado em 1969, a presença de Raymond Williams nas produções discentes nacionais indica a formação de uma tradição interessada em afinar o repertório intelectual das universidades brasileiras com a inclusão dos estudos do autor galês, que já apresenta raízes e que também já se encarregou de carregar seu nome galês para diferentes espaços universitários.

\section{Referências}

ABREU, Márcia; MOLLIER, Jean-Yves. Circulação transatlântica dos impressos - a globalização da cultura no século XIX. In: ABREU, M. (Org.). Romances em movimentos: a circulação transatlântica dos impressos (1789-1914). Campinas: Editora da Unicamp, 2016, p. 10-14.

CEVASCO, Maria Elisa. Para ler Raymond Williams. São Paulo: Paz e Terra, 2001.

CEVASCO, Maria Elisa. Prefácio. In: WILlIAMS, R. Palavras-chave: um vocabulário de cultura e sociedade. São Paulo: Boitempo, 2007, p. 09-20. 
MALANDRIN, Hiago Vaccaro. Sobre Raymond Williams e a perspectiva de natureza: a circulação transatlântica de O Campo e a Cidade no Brasil (1989-2019). 2021. Dissertação (Mestrado em Educação) - Faculdade de Educação, Universidade Estadual de Campinas. Campinas. 2021.

MORETTI, Franco. Atlas do romance europeu - 1800-1900. São Paulo: Editora Boitempo, 2003.

PAIXÃO, Alexandro Henrique. Linhagens interpretativas e cesuras epistemológicas no pensamento social brasileiro sobre Raymond Williams. In: ENCONTRO ANUAL DA ANPOCS, 42., Caxambu, 2018. Anais... Caxambu, MG, 2018. p. 01-25. Disponível em: http://www.anpocs.com/index.php/papers-40-encontro-3/gt-31/gt23-24/11308-linhagens-

interpretativas-e-cesuras-epistemologicasno-pensamento-social-brasileiro-sobre-raymondwilliams/file. Acesso em: 10 out. 2021.

WILLIAMS, Raymond. O campo e a cidade: na história e na literatura. São Paulo: Companhias das Letras, 2000.

WILLIAMS, Raymond. Tragédia moderna. São Paulo: Cosac \& Naify, 2002.

\section{Sobre o autor}

Hiago Vaccaro Malandrin. Mestre em Educação pela Faculdade de Educação da Universidade Estadual de Campinas (FE/UNICAMP), com dissertação intitulada "Sobre Raymond Williams e a perspectiva de natureza: a circulação transatlântica de $O$ Campo e a Cidade no Brasil (1989-2019)", financiada pela Fundação de Amparo à Pesquisa do Estado de São Paulo (processo FAPESP no 2019/00323-0).

E-mail: hiago.malandrin@gmail.com. 
RAYMOND WILLIAMS NO ESPAÇO DAS PRODUÇÕES DISCENTES NO ESTADO DE SÃO PAULO...

\section{Anexo}

Apresentação dos dados de produções discentes consultados para a submissão:

Raymond Williams no espaço das produções discentes no Estado de São Paulo: USP, Unesp e Unicamp (2004-2020)

\section{UNICAMP - Universidade Estadual de Campinas}

\begin{tabular}{|c|c|c|c|c|c|}
\hline Produção & Título & Autor & Ano & Orientação & Instituto \\
\hline Dissertação & $\begin{array}{c}\text { A construção dos planos de } \\
\text { desenvolvimento da unidade no projeto } \\
\text { pedagogico de duas creches de Jundiai }\end{array}$ & Celante, Licia Gobbi & 2005 & Vera Lucia Sabongi De Rossi & $\begin{array}{l}\text { Faculdade de } \\
\text { Educação }\end{array}$ \\
\hline Dissertação & Arte e conflito social & Moya, Cyntia Malaguti & 2016 & Liliana Rolfsen Petrilli Segnini & $\begin{array}{l}\text { Faculdade de } \\
\text { Educação }\end{array}$ \\
\hline Dissertação & $\begin{array}{c}\text { Cinema e sociedade: sobre a ditadura } \\
\text { militar no Brasil }\end{array}$ & Leme, Caroline Gomes & 2011 & $\begin{array}{l}\text { Orientador: Marcelo Siqueira } \\
\text { Ridenti }\end{array}$ & $\begin{array}{l}\text { Instituto de Filosofia e } \\
\text { Ciências Humanas }\end{array}$ \\
\hline Dissertação & $\begin{array}{l}\text { Democracia nos livros didáticos de } \\
\text { Sociologia para o Ensino Médio }\end{array}$ & Sousa, Raoni Gomes de & 2019 & Márcia Lopes Reis & $\begin{array}{l}\text { Instituto de Filosofia e } \\
\text { Ciências Humanas }\end{array}$ \\
\hline Dissertação & $\begin{array}{c}\text { Tradição, inovação e historicidade no } \\
\text { materialismo cultural de Raymond } \\
\text { Williams }\end{array}$ & Baute, Carla Rocha & 2020 & Silvana Barbosa Rubino & $\begin{array}{l}\text { Instituto de Filosofia e } \\
\text { Ciências Humanas }\end{array}$ \\
\hline TCC & $\begin{array}{c}\text { A natureza e a cultura em Wuthering } \\
\text { Heights, de Emily Brontë }\end{array}$ & Hirayama, Isabela & 2012 & Mário Luiz Frungillo & $\begin{array}{l}\text { Instituto de Estudos } \\
\text { da Linguagem }\end{array}$ \\
\hline TCC & $\begin{array}{c}\text { Proposições pedagógicas e socialistas no } \\
\text { pós-guerra : a longa revolução de } \\
\text { Raymond Williams }\end{array}$ & $\begin{array}{l}\text { Lisboa, Tâmela Adriani } \\
\text { Sousa }\end{array}$ & 2015 & Alexandro Henrique Paixão & $\begin{array}{l}\text { Faculdade de } \\
\text { Educação }\end{array}$ \\
\hline Tese & $\begin{array}{c}\text { Enquanto isso, em São Paulo... : à } \\
\text { l'époque do Cinema Novo, um cinema } \\
\text { paulista no "entre-lugar" }\end{array}$ & Leme, Caroline Gomes & 2016 & Marcelo Siqueira Ridenti & $\begin{array}{l}\text { Instituto de Filosofia e } \\
\text { Ciências Humanas }\end{array}$ \\
\hline
\end{tabular}




\section{USP - Universidade de São Paulo}

\begin{tabular}{|c|c|c|c|c|c|}
\hline Produção & Título & Autor & Ano & Orientação & Instituto \\
\hline Dissertação & $\begin{array}{l}\text { Crítica e modernidade em Raymond } \\
\text { Williams }\end{array}$ & Rivetti, Ugo Urbano Casares & 2015 & Musse, Ricardo & $\begin{array}{l}\text { Faculdade de Filosofia, } \\
\text { Letras e Ciências } \\
\text { Humanas }\end{array}$ \\
\hline Dissertação & $\begin{array}{c}\text { A concepção da tragédia moderna } \\
\text { em 'The crucible' e 'A view from the } \\
\text { bridge' de Arthur Miller }\end{array}$ & Leme, Viviane Maria & 2007 & Betti, Maria Silvia & $\begin{array}{l}\text { Faculdade de Filosofia, } \\
\text { Letras e Ciências } \\
\text { Humanas }\end{array}$ \\
\hline Dissertação & $\begin{array}{l}\text { Short cuts de Robert Altman: atalhos } \\
\text { para as formas de ilusão } \\
\text { contemporâneas }\end{array}$ & $\begin{array}{c}\text { Soares, Marcos Cesar de } \\
\text { Paula }\end{array}$ & 2007 & Soares, Marcos Cesar de Paula & $\begin{array}{l}\text { Faculdade de Filosofia, } \\
\text { Letras e Ciências } \\
\text { Humanas }\end{array}$ \\
\hline Dissertação & $\begin{array}{l}\text { O processo de legitimação cultural } \\
\text { das histórias em quadrinhos }\end{array}$ & $\begin{array}{c}\text { Carvalho, Beatriz Sequeira } \\
\text { de }\end{array}$ & 2017 & $\begin{array}{l}\text { Vergueiro, Waldomiro de } \\
\text { Castro Santos }\end{array}$ & $\begin{array}{c}\text { Escola de Comunicações } \\
\text { e Artes }\end{array}$ \\
\hline Dissertação & $\begin{array}{l}\text { De Amélias e Barracões: a noção de } \\
\text { saudade na obra de Ataulfo Alves }\end{array}$ & Faria, Amanda Beraldo & 2015 & $\begin{array}{l}\text { Silveira Junior, Walter Garcia } \\
\text { da }\end{array}$ & $\begin{array}{l}\text { Instituto de Estudos } \\
\text { Brasileiros }\end{array}$ \\
\hline Dissertação & $\begin{array}{c}\text { Futebol, Cultura e Utopia: uma } \\
\text { leitura de À procura de Eric, de Ken } \\
\text { Loach }\end{array}$ & Fernandes, André Luís Reis & 2016 & $\begin{array}{l}\text { Cevasco, Maria Elisa Burgos } \\
\text { Pereira da Silva }\end{array}$ & $\begin{array}{l}\text { Faculdade de Filosofia, } \\
\text { Letras e Ciências } \\
\text { Humanas }\end{array}$ \\
\hline Dissertação & $\begin{array}{l}\text { 'Literapalco' em Lygia Bojunga: arte } \\
\text { como projeto de vida }\end{array}$ & $\begin{array}{l}\text { Florencio, Cristiane } \\
\text { Figueiredo }\end{array}$ & 2019 & $\begin{array}{l}\text { Mendes, Maria dos Prazeres } \\
\text { Santos }\end{array}$ & $\begin{array}{l}\text { Faculdade de Filosofia, } \\
\text { Letras e Ciências } \\
\text { Humanas }\end{array}$ \\
\hline Dissertação & $\begin{array}{l}\text { Mesmo céu, mesmo CEP: produção } \\
\text { literária na periferia de São Paulo }\end{array}$ & Leite, Antonio Eleilson & 2014 & Mello, Jefferson Agostini & $\begin{array}{c}\text { Escola de Comunicações } \\
\text { e Artes }\end{array}$ \\
\hline Dissertação & $\begin{array}{l}\text { As gibitecas como polos } \\
\text { fomentadores de cultura e de } \\
\text { exercício da cidadania }\end{array}$ & $\begin{array}{c}\text { Marino, Daniela dos Santos } \\
\text { Domingues }\end{array}$ & 2018 & $\begin{array}{l}\text { Vergueiro, Waldomiro de } \\
\text { Castro Santos }\end{array}$ & $\begin{array}{c}\text { Escola de Comunicações } \\
\text { e Artes }\end{array}$ \\
\hline Dissertação & $\begin{array}{l}\text { Análise formal de All my sons e de } \\
\text { An enemy of the people, de Arthur } \\
\text { Miller }\end{array}$ & Russo, Thiago Pereira & 2014 & Betti, Maria Silvia & $\begin{array}{l}\text { Faculdade de Filosofia, } \\
\text { Letras e Ciências } \\
\text { Humanas }\end{array}$ \\
\hline Dissertação & $\begin{array}{l}\text { Sofrimento, solidão e desordem: a } \\
\text { representação trágica como meio } \\
\text { político no cinema de Leon Hirszman }\end{array}$ & $\begin{array}{l}\text { Takeda, Anna Carolina } \\
\text { Botelho }\end{array}$ & 2017 & Carelli, Fabiana Buitor & $\begin{array}{c}\text { Faculdade de Filosofia, } \\
\text { Letras e Ciências } \\
\text { Humanas }\end{array}$ \\
\hline
\end{tabular}


RAYMOND WILLIAMS NO ESPAÇO DAS PRODUÇÕES DISCENTES NO ESTADO DE SÃO PAULO...

\begin{tabular}{|c|c|c|c|c|c|}
\hline Dissertação & $\begin{array}{c}\text { Reafirmando uma nação: a figuração } \\
\text { da identidade nacional norte- } \\
\text { americana nas obras de Laura Ingalls } \\
\text { Wilder }\end{array}$ & $\begin{array}{c}\text { Tavares, Fabiana Valeria da } \\
\text { Silva }\end{array}$ & 2007 & $\begin{array}{c}\text { Cevasco, Maria Elisa Burgos } \\
\text { Pereira da Silva }\end{array}$ & $\begin{array}{l}\text { Faculdade de Filosofia, } \\
\text { Letras e Ciências } \\
\text { Humanas }\end{array}$ \\
\hline Dissertação & $\begin{array}{c}\text { Laerte 'vestido de mulher': uma } \\
\text { investigação sobre a representação } \\
\text { de gênero e sexualidade na mídia }\end{array}$ & $\begin{array}{l}\text { Bucchioni, Tulio Heleno de } \\
\text { Aguiar }\end{array}$ & 2016 & Almeida, Heloisa Buarque de & $\begin{array}{l}\text { Faculdade de Filosofia, } \\
\text { Letras e Ciências } \\
\text { Humanas }\end{array}$ \\
\hline TCC & $\begin{array}{c}\text { A cultura como fator de sucesso } \\
\text { financeiro nas organizações, baseado } \\
\text { no Competing Values Framework }\end{array}$ & Gobbi, Gabriel Zamboni & 2012 & Mateus Cecílio Gerolamo & $\begin{array}{c}\text { Escola De Engenharia De } \\
\text { São Carlos }\end{array}$ \\
\hline TCC & $\begin{array}{c}\text { O Estado brasileiro e algumas suas } \\
\text { políticas elétricas - Eletrificação e } \\
\text { Naturalização }\end{array}$ & Gonçalves, Bruno Peres & 2016 & Anselmo Alfredo & $\begin{array}{l}\text { Faculdade de Filosofia } \\
\text { Letras e Ciências } \\
\text { Humanas }\end{array}$ \\
\hline TCC & $\begin{array}{l}\text { Estudos hidrológicos aplicados em } \\
\text { projetos de urbanismo de impacto } \\
\text { reduzido: uma terceira margem de } \\
\text { possibilidades para a Bacia Santa } \\
\text { Maria do Leme, em São Carlos/SP }\end{array}$ & Oyama, Augusto Cesar & 2019 & Rodrigo de Melo Porto & $\begin{array}{c}\text { Escola De Engenharia De } \\
\text { São Carlos }\end{array}$ \\
\hline Tese & $\begin{array}{c}\text { Dois modos de ler: o poder de } \\
\text { aferição da crítica materialista em } \\
\text { Raymond Williams e Roberto } \\
\text { Schwarz }\end{array}$ & Morelli, Adriana Fernandes & 2010 & $\begin{array}{c}\text { Cevasco, Maria Elisa Burgos } \\
\text { Pereira da Silva }\end{array}$ & $\begin{array}{l}\text { Faculdade de Filosofia, } \\
\text { Letras e Ciências } \\
\text { Humanas }\end{array}$ \\
\hline Tese & $\begin{array}{c}\text { Marxismo, comunicação e cultura - } \\
\text { Raymond Williams e o materialismo } \\
\text { cultural }\end{array}$ & Azevedo, Fábio Palácio de & 2014 & Frederico, Celso & $\begin{array}{c}\text { Escola de Comunicações } \\
\text { e Artes }\end{array}$ \\
\hline Tese & Materialismo cultural & Glaser, André Luiz & 2008 & $\begin{array}{c}\text { Cevasco, Maria Elisa Burgos } \\
\text { Pereira da Silva }\end{array}$ & $\begin{array}{l}\text { Faculdade de Filosofia, } \\
\text { Letras e Ciências } \\
\text { Humanas }\end{array}$ \\
\hline Tese & $\begin{array}{l}\text { Direitos culturais e políticas } \\
\text { públicas: os marcos normativos do } \\
\text { Sistema Nacional da Cultura. }\end{array}$ & Oliveira, Danilo Júnior de & 2015 & Oliveira, Dennis de & Faculdade de Direito \\
\hline Tese & $\begin{array}{l}\text { A reinvenção do trabalhismo no } \\
\text { 'vulcão do inferno': um estudo sobre } \\
\text { metalúrgicos e têxteis de São Paulo. }\end{array}$ & Pereira Neto, Murilo Leal & 2006 & Iokoi, Zilda Marcia Gricoli & $\begin{array}{l}\text { Faculdade de Filosofia, } \\
\text { Letras e Ciências } \\
\text { Humanas }\end{array}$ \\
\hline
\end{tabular}


RAYMOND WILLIAMS NO ESPAÇO DAS PRODUÇÕES DISCENTES NO ESTADO DE SÃO PAULO...

\begin{tabular}{|c|c|c|c|c|c|}
\hline $\begin{array}{c}\text { Tese } \\
\text { UNESP - Un }\end{array}$ & $\begin{array}{l}\text { A fábrica, o bairro, o sindicalismo e a } \\
\text { política (1950-1964) } \\
\text { Debaixo do 'Pogréssio': urbanização, } \\
\text { cultura e experiência popular em } \\
\text { João Rubinato e outros sambistas } \\
\text { paulistanos (1951-1969) } \\
\text { versidade Estadual Paulista }\end{array}$ & Silva, Marcos Virgílio da & 2011 & Gitahy, Maria Lucia Caira & $\begin{array}{c}\text { Faculdade de } \\
\text { Arquitetura e Urbanismo }\end{array}$ \\
\hline Produção & Título & Autor & Ano & Orientação & Instituto \\
\hline Dissertação & $\begin{array}{c}\text { Dois cisnes à procura de um } \\
\text { personagem: uma leitura } \\
\text { pirandelliana do filme Cisne Negro }\end{array}$ & $\begin{array}{l}\text { Santos, Carlos Felipe da Silva } \\
\text { dos }\end{array}$ & 2014 & Betella, Gabriela Kvacek & Letras - FCLAS \\
\hline Dissertação & $\begin{array}{l}\text { O Brasil que não é bem assim: } \\
\text { representações do Brasil na } \\
\text { cobertura da Copa do Mundo } 2014 \\
\text { pelo jornal The Guardian }\end{array}$ & $\begin{array}{c}\text { Vieira, Maria Carolina Silva } \\
\text { Rocha }\end{array}$ & 2016 & $\begin{array}{c}\text { Vicente, Maximiliano } \\
\text { Martin }\end{array}$ & Comunicação - FAAC \\
\hline Dissertação & $\begin{array}{c}\text { Materialidades na dramaturgia } \\
\text { contemporânea: o Prêmio Shell em } \\
\text { São Paulo (2005 - 2015) }\end{array}$ & Gomes, Marcos Nogueira & 2017 & $\begin{array}{c}\text { Lázaro de Ortecho Ramírez, } \\
\text { José Manuel }\end{array}$ & Artes - IA \\
\hline Dissertação & $\begin{array}{c}\text { Crítica e autocrítica da } \\
\text { modernidade: crise civilizatória e } \\
\text { utopia anticapitalista em Michael } \\
\text { Löwy }\end{array}$ & Querido, Fabio Mascaro & 2011 & Pinassi, Maria Orlanda & Ciências Sociais - FCLAR \\
\hline Dissertação & $\begin{array}{c}\text { O fazer intelectual brasileiro } \\
\text { (1930-1946): Rachel de Queiroz e } \\
\text { o Congresso de } 1946\end{array}$ & Alves, Plauto Daniel Santos & 2015 & Pinheiro, Marcos Sorrilha & História - FCHS \\
\hline Dissertação & $\begin{array}{l}\text { Arthur Poerner entre estudantes e } \\
\text { intelectuais (1965-1968): } \\
\text { representações intelectuais no } \\
\text { jornal Folha da Semana e no livro } 0 \\
\text { Poder Jovem }\end{array}$ & Castro, Thiago Bicudo & 2016 & Czajka, Rodrigo & Ciências Sociais - FFC \\
\hline Dissertação & $\begin{array}{l}\text { O naturalismo como técnica de } \\
\text { representação realista: uma } \\
\text { proposta teórico-crítica para } \\
\text { BaléRalé, de Marcelino Freire }\end{array}$ & Silva, Paulo Ricardo Moura da & 2016 & Scheel, Márcio & Letras - IBILCE \\
\hline
\end{tabular}


RAYMOND WILLIAMS NO ESPAÇO DAS PRODUÇÕES DISCENTES NO ESTADO DE SÃO PAULO...

"É tudo baiano, mas é misturado": dinâmica migratória em Américo Brasiliense, aspectos de um problema nacional

Almeida, Iara Lalesca Calazans de

Ciências Sociais - FCLAR

Palmeira do mangue não vive na areia de Copacabana: o samba do

Dissertação Estácio e a formação de uma esfera pública popular em fins dos anos 1920

"Enquanto governa a maldade, a gente canta a liberdade": Coletivo

Dissertação de Cultura do MST: caminhos para a criação de uma cultura contrahegemônica

\begin{tabular}{|c|c|c|c|c|c|}
\hline Dissertação & $\begin{array}{l}\text { Manifestações do herói trágico em } \\
\text { O tempo e o vento }\end{array}$ & Borgato, Raphael & 2011 & $\begin{array}{c}\text { Maas, Wila Patrícia Marzari } \\
\text { Dinardo }\end{array}$ & $\begin{array}{l}\text { Estudos Literários - } \\
\text { FCLAR }\end{array}$ \\
\hline Dissertação & $\begin{array}{c}\text { A linguagem da violência nos } \\
\text { contos de Famílias terrivelmente } \\
\text { felizes de Marçal Aquino }\end{array}$ & Mendes, Fábio Marques & 2014 & Scheel, Márcio & Letras - IBILCE \\
\hline Dissertação & $\begin{array}{l}\text { 'Procura-se Mecenas': música } \\
\text { independente e indústria } \\
\text { fonográfica na trajetória artística } \\
\text { do Grupo Um (1976 -1984) }\end{array}$ & Ruiz, Renan Branco & 2017 & Fenerick, José Adriano & História - FCHS \\
\hline Dissertação & $\begin{array}{l}\text { A gastronomia como bem } \\
\text { simbólico e fator de distinção: uma } \\
\text { análise do caderno Paladar, do } \\
\text { jornal O Estado de São Paulo }\end{array}$ & Brait, Paula Malatian & 2010 & Ventura, Mauro de Souza & Comunicação - FAAC \\
\hline Dissertação & $\begin{array}{l}\text { Do Cinema Novo à Política } \\
\text { Nacional de Cultura: a } \\
\text { representação dos nordestinos do } \\
\text { Brasil sob o olhar de Nelson } \\
\text { Pereira dos Santos (1960-1980) }\end{array}$ & $\begin{array}{l}\text { Medeiros, Carlos Gabriel } \\
\text { Sardinha de }\end{array}$ & 2020 & Silva, Marcia Pereira da & História - FCHS \\
\hline Dissertação & $\begin{array}{l}\text { Operários e camponeses: a } \\
\text { repercussão da Revolução }\end{array}$ & Sousa, Fábio da Silva & 2010 & $\begin{array}{c}\text { Barbosa, Carlos Alberto } \\
\text { Sampaio }\end{array}$ & História - FCLAS \\
\hline
\end{tabular}

Paiva, Carlos Eduardo Amaral

\section{de \\ 2009 Souza, Eliana Maria de Melo Ciências Sociais - FCLAR}

Desenvolvimento

territorial na América

Latina e Caribe - IPPRI

Brennand, Evelaine Martines 2017 Aparecida Caprioglio de 
RAYMOND WILLIAMS NO ESPAÇO DAS PRODUÇÕES DISCENTES NO ESTADO DE SÃO PAULO...

Mexicana na imprensa operária brasileira (1910-1920)

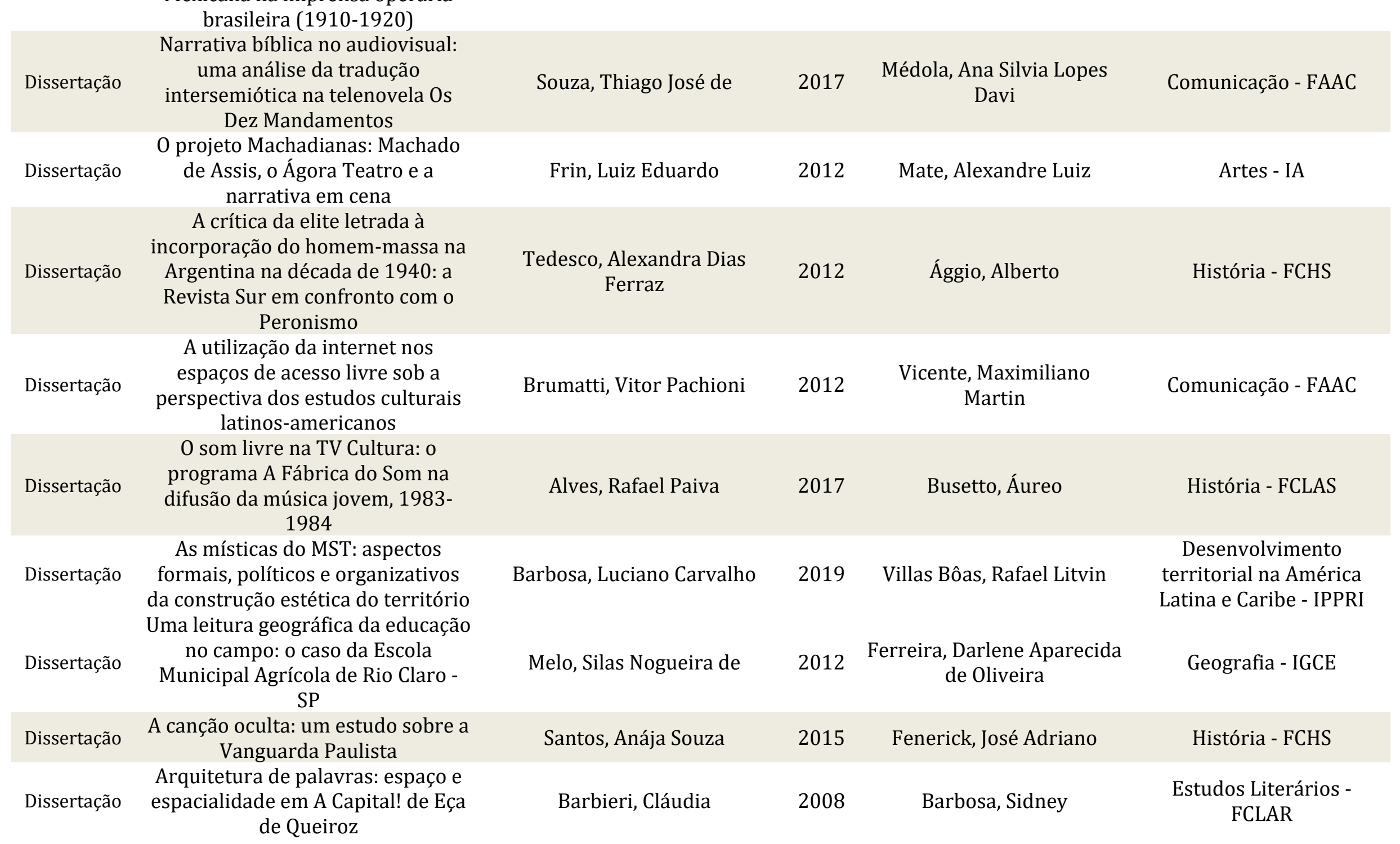


RAYMOND WILLIAMS NO ESPAÇO DAS PRODUÇÕES DISCENTES NO ESTADO DE SÃO PAULO...

\begin{tabular}{|c|c|c|c|c|c|}
\hline Dissertação & $\begin{array}{c}\text { Deslocamento, interculturalidade e } \\
\text { transitividade migratória em filmes } \\
\text { dirigidos por Karim Aïnouz }\end{array}$ & Medeiros, André Aparecido & 2018 & Cabral, Raquel & Comunicação - FAAC \\
\hline Dissertação & $\begin{array}{l}\text { As estratégias discursivas da } \\
\text { comunicação dirigida em pontos de } \\
\text { venda do HSBC }\end{array}$ & $\begin{array}{l}\text { Ceschin, Michelle Beatriz } \\
\text { Godoy Santos }\end{array}$ & 2016 & $\begin{array}{c}\text { Médola, Ana SílviaLopes } \\
\text { Davi }\end{array}$ & Comunicação - FAAC \\
\hline Dissertação & $\begin{array}{l}\text { A Discoteca Pública Municipal de } \\
\text { São Paulo: um projeto modernista } \\
\text { para a música nacional }\end{array}$ & Moya, Fernanda Nunes & 2010 & $\begin{array}{c}\text { Machado, Carlos Eduardo } \\
\text { Jordão }\end{array}$ & História - FCLAS \\
\hline Dissertação & $\begin{array}{c}\text { Alma do espetáculo ou público } \\
\text { pagante?: uma análise } \\
\text { culturológica sobre as } \\
\text { representações do torcedor de } \\
\text { futebol na mídia esportiva } \\
\text { impressa }\end{array}$ & Cintra Sobrinho, David & 2005 & Bertolli Filho, Cláudio & Comunicação - FAAC \\
\hline Dissertação & $\begin{array}{l}\text { As políticas de fomento à cultura } \\
\text { no município de Franca: uma } \\
\text { análise das políticas de fomento à } \\
\text { cultura no município de Franca/SP } \\
\text { pós-redemocratização do Brasil }\end{array}$ & Mamedio, João Batista & 2018 & $\begin{array}{l}\text { Mendes, Alexandre } \\
\text { Marques }\end{array}$ & $\begin{array}{c}\text { Planejamento e Análise } \\
\text { de Políticas Públicas - } \\
\text { FCHS }\end{array}$ \\
\hline Dissertação & $\begin{array}{l}\text { Comunicação intercultural em } \\
\text { empresas de treinamento de } \\
\text { profissionais em processo de } \\
\text { internacionalização }\end{array}$ & Gomes, Alana Carolina & 2019 & Cabral, Raquel & Comunicação - FAAC \\
\hline Dissertação & $\begin{array}{l}\text { Companhia Estável de Teatro: a } \\
\text { práxis como processo de criação }\end{array}$ & Szot, Daniela Gianpietro & 2016 & Mate, Alexandre Luiz & Artes - IA \\
\hline Dissertação & $\begin{array}{l}\text { O teatro político de rua praticado } \\
\text { pelos coletivos ALMA e Dolores: } \\
\text { estéticas de combate e semeadura }\end{array}$ & Araújo, Alexandre Falcão de & 2013 & Mate, Alexandre Luiz & Artes - IA \\
\hline Dissertação & $\begin{array}{l}\text { Educação e trabalho em } \\
\text { movimentos sociais: princípios } \\
\text { educativos transcendentes e } \\
\text { comuns ao Movimento dos } \\
\text { Trabalhadores Rurais Sem Terra }\end{array}$ & Silva, Cláudio Rodrigues da & 2014 & Ri, Neusa Maria Dal & Educação - FFC \\
\hline
\end{tabular}


RAYMOND WILLIAMS NO ESPAÇO DAS PRODUÇÕES DISCENTES NO ESTADO DE SÃO PAULO...

(MST), aos socialistas utópicos

owenistas e aos cartistas britânicos

\begin{tabular}{|c|c|c|c|c|c|}
\hline Dissertação & $\begin{array}{c}\text { Cia. Artehúmus de Teatro: as raízes } \\
\text { sociais e poéticas da fertilidade } \\
\text { artística }\end{array}$ & Guimarães, Natália & 2016 & $\begin{array}{l}\text { Romano, Lúcia Regina } \\
\text { Vieira }\end{array}$ & Artes - IA \\
\hline Dissertação & $\begin{array}{c}\text { A cultura participativa no } \\
\text { YouTube: relação entre ídolos-fãs } \\
\text { em canais brasileiros }\end{array}$ & Souza, Caroline Mazzer de & 2020 & Gobbi, Maria Cristina & Comunicação - FAAC \\
\hline Dissertação & $\begin{array}{l}\text { Mediação da leitura em bibliotecas } \\
\text { públicas }\end{array}$ & Rasteli, Alessandro & 2013 & Cavalcante, Lídia Eugênia & $\begin{array}{l}\text { Ciência da Informação - } \\
\text { FFC }\end{array}$ \\
\hline Dissertação & $\begin{array}{l}\text { História da construção do conceito } \\
\text { de evolução biológica: } \\
\text { possibilidades de uma percepção } \\
\text { dinâmica da ciência pelos } \\
\text { professores de biologia }\end{array}$ & $\begin{array}{l}\text { Meglhioratti, Fernanda } \\
\text { Aparecida }\end{array}$ & 2004 & $\begin{array}{l}\text { Bortolozzi, Jehud; Caldeira, } \\
\text { Ana Maria de Andrade }\end{array}$ & $\begin{array}{c}\text { Educação para a Ciência - } \\
\text { FC }\end{array}$ \\
\hline Dissertação & $\begin{array}{c}\text { De coadjuvante a protagonista? Os } \\
\text { desafios da diversidade cultural, da } \\
\text { produção audiovisual } \\
\text { independente e regional na TV } \\
\text { Paga }\end{array}$ & Pessotto, Ana Heloiza Vita & 2016 & $\begin{array}{c}\text { Kerbauy, Maria Teresa } \\
\text { Miceli }\end{array}$ & Comunicação - FAAC \\
\hline Dissertação & $\begin{array}{c}\text { Assombros e escombros da } \\
\text { modernidade no teatro de Hilda } \\
\text { Hilst }\end{array}$ & $\begin{array}{l}\text { Zago, Carlos Eduardo dos } \\
\text { Santos }\end{array}$ & 2012 & $\begin{array}{l}\text { Martins, Gilberto } \\
\text { Figueiredo }\end{array}$ & Letras - FCLAS \\
\hline Dissertação & $\begin{array}{l}\text { Agronegócio e indústria cultural: } \\
\text { estratégias das empresas para a } \\
\text { construção da hegemonia }\end{array}$ & Chã, Ana Manuela de Jesus & 2016 & Villas Bôas, Rafael Litvin & $\begin{array}{l}\text { Desenvolvimento } \\
\text { Territorial na América } \\
\text { Latina e Caribe - IPPRI }\end{array}$ \\
\hline Dissertação & $\begin{array}{l}\text { Febre na selva: a Amazônia na } \\
\text { interpretação de Euclides da Cunha }\end{array}$ & Ribeiro, Fabrício Leonardo & 2007 & $\begin{array}{l}\text { Naxara, Márcia Regina } \\
\text { Capelari }\end{array}$ & História - FCHS \\
\hline Dissertação & $\begin{array}{l}\text { Linguagens urbanas e } \\
\text { modernidade na Babel amalucada: } \\
\text { cartas caipiras em periódicos } \\
\text { paulistanos (1900-1926) }\end{array}$ & Rodrigues, Beatriz & 2015 & $\begin{array}{l}\text { Naxara, Márcia Regina } \\
\text { Capelari }\end{array}$ & História - FCHS \\
\hline Dissertação & $\begin{array}{l}0 \text { galope nordestino diante do } \\
\text { parque industrial: o projeto }\end{array}$ & Santos, Nívea Lins & 2015 & Fenerick, José Adriano & História - FCHS \\
\hline
\end{tabular}


RAYMOND WILLIAMS NO ESPAÇO DAS PRODUÇÕES DISCENTES NO ESTADO DE SÃO PAULO...

\begin{tabular}{|c|c|c|c|c|c|}
\hline & $\begin{array}{c}\text { estético do Quinteto Armorial no } \\
\text { Brasil moderno }\end{array}$ & & & & \\
\hline Dissertação & $\begin{array}{l}\text { Entre o mito e a técnica: } \\
\text { representações de natureza em } \\
\text { fontes fotográficas (Londrina, } \\
\text { 1934-1944) }\end{array}$ & André, Richard Gonçalves & 2006 & Camargo, Célia Reis & História - FCLAS \\
\hline Dissertação & $\begin{array}{c}\text { A linguagem da violência nos } \\
\text { contos de Famílias terrivelmente } \\
\text { felizes de Marçal Aquino }\end{array}$ & Mendes, Fábio Marques & 2014 & Scheel, Márcio & Letras - IBILCE \\
\hline Dissertação & $\begin{array}{c}\text { Relações de Trabalho no } \\
\text { Assentamento Contestado (PR): } \\
\text { Contradições de Classe e Desafios } \\
\text { analíticos }\end{array}$ & Orzekovski, Nei & 2014 & Thomaz Júnior, Antonio & Geografia - FCT \\
\hline Dissertação & $\begin{array}{l}\text { Da enciclopédia à Wikipédia: o } \\
\text { conhecimento em circulação }\end{array}$ & Cezario, Natalia Trevisan & 2011 & Valdemarin, Vera Teresa & $\begin{array}{l}\text { Educação Escolar - } \\
\text { FCLAR }\end{array}$ \\
\hline Dissertação & $\begin{array}{l}\text { Práticas de leitura de estudantes } \\
\text { do curso de pedagogia: entre } \\
\text { apropriações e formalidades }\end{array}$ & Silva, Aline Ramiro da & 2015 & Valdemarin, Vera Teresa & Educação - IBRC \\
\hline Dissertação & $\begin{array}{c}\text { Ensino primário tipicamente rural } \\
\text { no Estado de São Paulo: um estudo } \\
\text { sobre as Granjas Escolares, os } \\
\text { Grupos Escolares Rurais e as } \\
\text { Escolas Típicas Rurais (1933- } \\
\text { 1968) }\end{array}$ & Moraes, Agnes Iara Domingos & 2014 & Souza, Rosa Fátima de & Educação - FFC \\
\hline Dissertação & $\begin{array}{l}\text { O livro didático e o ensino de } \\
\text { História em uma escola pública } \\
\text { situada no interior paulista }\end{array}$ & $\begin{array}{l}\text { Zacheu, Aline Aparecida } \\
\text { Pereira }\end{array}$ & 2015 & Celeste Filho, Macioniro & $\begin{array}{c}\text { Docência para a } \\
\text { Educação Básica - FC }\end{array}$ \\
\hline Dissertação & $\begin{array}{c}\text { Narrativas negadas: estratégias de } \\
\text { resistência à discriminação } \\
\text { planejada }\end{array}$ & Brito, Marlene Oliveira & 2017 & Machado, Vitor & $\begin{array}{c}\text { Docência para a } \\
\text { Educação Básica - FC }\end{array}$ \\
\hline Dissertação & $\begin{array}{c}\text { Televisão digital: interação e } \\
\text { usabilidade }\end{array}$ & $\begin{array}{l}\text { Teixeira, Lauro Henrique de } \\
\text { Paiva }\end{array}$ & 2008 & $\begin{array}{l}\text { Médola, Ana Sílvia Lopes } \\
\text { Davi }\end{array}$ & Comunicação - FAAC \\
\hline
\end{tabular}


RAYMOND WILLIAMS NO ESPAÇO DAS PRODUÇÕES DISCENTES NO ESTADO DE SÃO PAULO...

Deslocamento, interculturalidade e

Dissertação transitividade migratória em filmes dirigidos por Karim Aïnouz

Do palco à mídia: análise estética

\section{Dissertação dos discursos jornalísticos sobre}

Aança

Medeiros, André Aparecido

2018

Cabral, Raquel

Comunicação - FAAC sobre o suplemento literário

Dissertação sabático, do jornal 0 Estado de S

$$
\text { Paulo }
$$

$\begin{array}{cc}\text { Cultura e violência: autores, } \\ \text { Dissertação } & \text { polêmicas e contribuições da }\end{array}$ literatura marginal

A programação em tempos de ubiquidade televisiva: um estudo

TCC direcionado ao plano de distribuição de conteúdos da TV UNESP

\begin{tabular}{|c|c|c|c|c|c|}
\hline TCC & $\begin{array}{l}\text { A implantação da televisão digital } \\
\text { terrestre na Espanha }\end{array}$ & $\begin{array}{l}\text { Nascimento, Raphael } \\
\text { Rodrigues }\end{array}$ & 2012 & $\begin{array}{l}\text { Carvalho, Juliano Maurício } \\
\text { de }\end{array}$ & $\begin{array}{l}\text { Faculdade de } \\
\text { Arquitetura, Artes e } \\
\text { Comunicação. }\end{array}$ \\
\hline TESE & $\begin{array}{l}\text { Tensões e ajustes entre tradição e } \\
\text { modernidade nas definições de } \\
\text { padrões da música sertaneja entre } \\
\text { os anos } 50 \text { e } 70\end{array}$ & Araújo, Lucas Antonio de & 2014 & Garcia, Tania da Costa & História - FCHS \\
\hline Tese & $\begin{array}{l}\text { Telejornalismo e sites de redes } \\
\text { sociais: um estudo sobre as } \\
\text { mudanças recentes no modo de } \\
\text { endereçamento do Jornal Nacional }\end{array}$ & Bevilaqua, Leire Mara & 2019 & Ventura, Mauro de Souza & Comunicação - FAAC \\
\hline Tese & $\begin{array}{c}\text { Uma estrutura de sentimento em } \\
\text { tempos autoritários: o romantismo } \\
\text { no cancioneiro de Zé Rodrix (1967- } \\
1979)\end{array}$ & Sousa, Rainer Gonçalves & 2020 & Pinheiro, Marcos Sorrilha & História - FCHS \\
\hline Tese & $\begin{array}{c}\text { Leituras do trágico sob a } \\
\text { perspectiva do romance realista: }\end{array}$ & Borgato, Rafhael & 2019 & $\begin{array}{c}\text { Maas, Wila Patrícia Marzari } \\
\text { Dinardo }\end{array}$ & $\begin{array}{l}\text { Estudos Literários - } \\
\text { FCLAR }\end{array}$ \\
\hline
\end{tabular}


RAYMOND WILLIAMS NO ESPAÇO DAS PRODUÇÕES DISCENTES NO ESTADO DE SÃO PAULO...

um estudo sobre Madame Bovary e Anna Kariênina

\begin{tabular}{|c|c|c|c|c|c|}
\hline Tese & $\begin{array}{l}\text { Realismo e intimismo no romance } \\
\text { brasileiro: o conceito de técnica } \\
\text { introdiccionista a partir da } \\
\text { perspectiva do discurso interior }\end{array}$ & Silva, Paulo Ricardo Moura da & 2020 & Scheel, Márcio & Letras - IBILCE \\
\hline Tese & $\begin{array}{c}\text { O uso dos dispositivos móveis e da } \\
\text { internet como parte da cultura } \\
\text { escolar de estudantes } \\
\text { universitários }\end{array}$ & Lopes, Eduarda Escila Ferreira & 2018 & Valdemarin, Vera Teresa & Educação - IBRC \\
\hline Tese & $\begin{array}{l}\text { Mark Twain: um patriota } \\
\text { antiimperialista e seu relato de } \\
\text { viagem em The innocents abroad } \\
\text { or the new pilgrim's progress }\end{array}$ & Doca, Heloisa Helou & 2006 & Cairo, Luiz Roberto Velloso & Letras - IBILCE \\
\hline Tese & $\begin{array}{l}\text { Representação do trabalho e } \\
\text { trabalho de representação em } \\
\text { narrativas seriadas televisivas } \\
\text { norte-americanas }\end{array}$ & $\begin{array}{l}\text { Carvalho, André Ferreira } \\
\text { Gomes de }\end{array}$ & 2018 & $\begin{array}{l}\text { Fernandes, Giséle } \\
\text { Manganelli }\end{array}$ & Letras - IBILCE \\
\hline Tese & $\begin{array}{l}\text { Visões de ruralidades: } \\
\text { personagens, paisagens e contextos } \\
\text { em obras literárias }\end{array}$ & Kim, Hyung Mi & 2013 & $\begin{array}{l}\text { Oliveira, Bernadete } \\
\text { Aparecida C. Castro }\end{array}$ & Geografia - IGCE \\
\hline Tese & $\begin{array}{c}\text { Black Paul: a soul music no Brasil } \\
\text { nos anos } 1970\end{array}$ & $\begin{array}{c}\text { Paiva, Carlos Eduardo Amaral } \\
\text { de }\end{array}$ & 2015 & Souza, Eliana Maria de Melo & Ciências Sociais - FCLAR \\
\hline Tese & $\begin{array}{c}\text { Nacionalismo musical e } \\
\text { brasilidade: uma revisão }\end{array}$ & Frungillo, Mário D & 2014 & Kerr, Dorotéa Machado & Música - IA \\
\hline Tese & $\begin{array}{c}\text { Nostalgia, fuga, prisão: campo e } \\
\text { cidade em três romances } \\
\text { brasileiros do século XX }\end{array}$ & Ignácio, Ewerton de Freitas & 2008 & Junior, Arnaldo Franco & Letras - IBILCE \\
\hline Tese & $\begin{array}{c}\text { A prosa literária de Bruno de } \\
\text { Menezes em perspectiva dialógica }\end{array}$ & Aquino, Ana Cleide Guimbal de & 2014 & $\begin{array}{l}\text { Marchezan, Renata Coelho; } \\
\text { Soares, Henrique Silvestre }\end{array}$ & $\begin{array}{l}\text { Linguística e Língua } \\
\text { Portuguesa - FCLAR }\end{array}$ \\
\hline Tese & $\begin{array}{c}\text { Elementos do trágico em Eça de } \\
\text { Queirós: A tragédia da Rua das } \\
\text { Flores e Os Maias }\end{array}$ & Leal, Luciana Ferreira & 2006 & Filho, Odil José de Oliveira & Letras - FCLAS \\
\hline
\end{tabular}


RAYMOND WILLIAMS NO ESPAÇO DAS PRODUÇÕES DISCENTES NO ESTADO DE SÃO PAULO...

Produção Cultural em Rondônia: a

Tese $\quad$ significação do cotidiano pelo viés literário

\begin{tabular}{|c|c|c|c|c|c|}
\hline & literário & & & & \\
\hline Tese & $\begin{array}{l}\text { A fabricação do urbano: civilidade, } \\
\text { modernidade e progresso em } \\
\text { Uberabinha-MG (1888-1929) }\end{array}$ & Dantas, Sandra Mara & 2009 & $\begin{array}{c}\text { Naxara, Márcia Regina } \\
\text { Capelari }\end{array}$ & História - FCHS \\
\hline Tese & $\begin{array}{l}\text { Da fotografia na cidade a cidade na } \\
\text { fotografia: Ribeirão Preto 1891- } \\
1923\end{array}$ & Marques, Higina Teixeira & 2015 & Tosi, Pedro Geraldo Saadi & História - FCHS \\
\hline Tese & $\begin{array}{l}\text { Épica, em perspectiva, miscigenada } \\
\text { e malandra: mergulhos em } \\
\text { processos criativos da Cia. Livre e } \\
\text { da Cia. Teatro Balagan trazem à } \\
\text { tona forma de produção do sujeito } \\
\text { teatro de grupo paulistano }\end{array}$ & Frin, Luiz Eduardo & 2017 & Mate, Alexandre & Artes - IA \\
\hline Tese & $\begin{array}{l}\text { O paraíso atrasado: a construção } \\
\text { do rural no Brasil através do } \\
\text { imaginário geográfico }\end{array}$ & Maia, Adriano Corrêa & 2015 & $\begin{array}{c}\text { Ferreira, Darlene Aparecida } \\
\text { de Oliveira }\end{array}$ & Geografia - IGCE \\
\hline Tese & $\begin{array}{l}\text { Entre a sacristia e o laboratório: os } \\
\text { intelectuais protestantes } \\
\text { brasileiros e a produção da cultura } \\
\text { (1903-1942) }\end{array}$ & Lima, Éber Ferreira Silveira & 2008 & Ferreira, Antonio Celso & História - FCLAS \\
\hline Tese & $\begin{array}{l}\text { "Tchau, querida": os } \\
\text { enquadramentos do Jornal } \\
\text { Nacional no processo de } \\
\text { impeachment }\end{array}$ & $\begin{array}{c}\text { Castanheira, Karol Natasha } \\
\text { Lourenço }\end{array}$ & 2018 & Bertolli Filho, Cláudio & Comunicação - FAAC \\
\hline Tese & $\begin{array}{l}\text { Aspectos do interesse pela leitura } \\
\text { literária: uma análise documental e } \\
\text { ficcional dos escritos de Machado } \\
\text { de Assis para O Cruzeiro (1878) }\end{array}$ & $\begin{array}{c}\text { Teixeira Júnior, Nelson de } \\
\text { Jesus }\end{array}$ & 2019 & Granja, Lucia & Letras - IBILCE \\
\hline Tese & $\begin{array}{l}\text { As associações de alunos das } \\
\text { escolas normais do Brasil e de } \\
\text { Portugal: apropriação e } \\
\text { representação (1906-1927) }\end{array}$ & Serra, Áurea Esteves & 2010 & Nery, Ana Clara Bortoleto & Educação - IBRC \\
\hline
\end{tabular}


RAYMOND WILLIAMS NO ESPAÇO DAS PRODUÇÕES DISCENTES NO ESTADO DE SÃO PAULO...

\begin{tabular}{|c|c|c|c|c|c|}
\hline Tese & $\begin{array}{l}\text { Além do rural: os vínculos topo- } \\
\text { biofílicos na interação visitantes e } \\
\text { paisagem rural em Itu - SP }\end{array}$ & Santos, Vera Lúcia dos & 2005 & $\begin{array}{l}\text { Machado, Lucy Marion } \\
\text { Calderini Philadelpho }\end{array}$ & Geografia - IGCE \\
\hline Tese & $\begin{array}{c}\text { A natureza no discurso fotográfico } \\
\text { da revista O Cruzeiro: paisagens e } \\
\text { imaginários no Brasil } \\
\text { desenvolvimentista 1954-1961 }\end{array}$ & Romanello, Jorge Luiz & 2006 & Camargo, Célia Reis & História - FCLAS \\
\hline Tese & $\begin{array}{l}\text { O Fio de Ariadne e o labirinto da } \\
\text { internet: geografia e tecnologia: a } \\
\text { dialética virtual x real, as redes e as } \\
\text { ruas: o ciberespaço como } \\
\text { dimensão socioespacial }\end{array}$ & $\begin{array}{l}\text { Figueiredo, Wellington dos } \\
\text { Santos }\end{array}$ & 2020 & $\begin{array}{c}\text { Magnoni, Maria da Graça } \\
\text { Mello }\end{array}$ & $\begin{array}{l}\text { Mídia e Tecnologia } \\
\text { (doutorado) - FAAC }\end{array}$ \\
\hline Tese & $\begin{array}{l}\text { Arte sem fronteiras. Londres, } \\
\text { Berlim, São Paulo e Rio de Janeiro: } \\
\text { olhares estéticos e capitalistas } \\
\text { sobre as células do poder lícito e } \\
\text { ilícito (séculos XVIII e XX) }\end{array}$ & Rocha, Denise & 2004 & Azevedo, Silvia Maria & Letras - FCLAS \\
\hline Tese & $\begin{array}{c}\text { Os processos formativos de } \\
\text { estudantes universitários } \\
\text { paranaenses e suas relações com } \\
\text { os artefatos digitais: uma proposta } \\
\text { de mediação didática colaborativa } \\
\text { baseada na cognição distribuída }\end{array}$ & $\begin{array}{l}\text { Moraes, Dirce Aparecida } \\
\text { Foletto de }\end{array}$ & 2017 & Lima, Claudia Maria de & Educação - FCT \\
\hline Tese & $\begin{array}{c}\text { Entre Verdugos e Sedutores: } \\
\text { Modernidade e (Des) } \\
\text { Mascaramento na Prosa de Hilda } \\
\text { Hilst }\end{array}$ & $\begin{array}{l}\text { Zago, Carlos Eduardo dos } \\
\text { Santos }\end{array}$ & 2018 & $\begin{array}{l}\text { Martins, Gilberto } \\
\text { Figueiredo }\end{array}$ & Letras - FCLAS \\
\hline Tese & $\begin{array}{l}\text { A circulação das ideias do } \\
\text { movimento pela ruralização do } \\
\text { ensino no Brasil (1930-1950) }\end{array}$ & Moraes, Agnes Iara Domingos & 2019 & Souza, Rosa Fátima & Educação - FFC \\
\hline Tese & $\begin{array}{c}\text { Educação em movimentos sociais: } \\
\text { princípios educativos comuns ao } \\
\text { movimento zapatista e ao } \\
\text { Movimento dos Trabalhadores }\end{array}$ & Silva, Cláudio Rodrigues da & 2019 & Dal Ri, Neusa Maria & Educação - FFC \\
\hline
\end{tabular}


RAYMOND WILLIAMS NO ESPAÇO DAS PRODUÇÕES DISCENTES NO ESTADO DE SÃO PAULO...

\begin{tabular}{|c|c|c|c|c|c|}
\hline Tese & $\begin{array}{c}\text { Itinerários, estruturas de } \\
\text { sociabilidades e ação política: } \\
\text { intelectuais de São Paulo na crise } \\
\text { do Império (1875-1889) }\end{array}$ & Correa, Rubens Arantes & 2014 & Malatian, Teresa Maria & História - FCHS \\
\hline Tese & $\begin{array}{c}\text { A etnografia literária de Guimarães } \\
\text { Rosa }\end{array}$ & Mendonça, Elizabeth da Silva & 2018 & $\begin{array}{l}\text { Falleiros, Flávia } \\
\text { Nascimento }\end{array}$ & Letras - IBILCE \\
\hline Tese & $\begin{array}{c}\text { Representação do trabalho e } \\
\text { trabalho de representação em } \\
\text { narrativas seriadas televisivas } \\
\text { norte-americanas }\end{array}$ & $\begin{array}{l}\text { Carvalho, André Ferreira } \\
\text { Gomes de }\end{array}$ & 2018 & $\begin{array}{l}\text { Fernandes, Giséle } \\
\text { Manganelli }\end{array}$ & Letras - IBILCE \\
\hline Tese & $\begin{array}{c}\text { As festas na constituição do sentido } \\
\text { de lugar nos bairros rurais dos } \\
\text { municípios paulistas de } \\
\text { Cordeirópolis e Piracicaba }\end{array}$ & Oliveira, Cibele Marto de & 2017 & $\begin{array}{l}\text { Ferreira, Darlene Aparecida } \\
\text { de Oliveira }\end{array}$ & Geografia - IGCE \\
\hline Tese & $\begin{array}{c}\text { Estética romântica germânica e a } \\
\text { paisagem em Humboldt: percurso } \\
\text { da geografia }\end{array}$ & Barbosa, Túlio & 2011 & $\begin{array}{l}\text { Nunes, João Osvaldo } \\
\text { Rodrigues }\end{array}$ & Geografia - FCT \\
\hline Tese & $\begin{array}{c}\text { A urdidura espacial do capital e do } \\
\text { trabalho no cerrado do sudoeste } \\
\text { goiano }\end{array}$ & Mendonça, Marcelo Rodrigues & 2004 & Júnior, Antonio Thomaz & Geografia - FCT \\
\hline Tese & $\begin{array}{c}\text { Natureza, tempo livre e } \\
\text { administração social: uma análise } \\
\text { das práticas de lazer em } \\
\text { Carrancas/MG }\end{array}$ & Farias, Márcio Norberto & 2008 & Franco, Renato Bueno & Ciências Sociais - FCLAR \\
\hline
\end{tabular}

